\title{
Investigating Causality between Global Experience and Global Competency for Undergraduates in Contemporary China's Higher Education: A Transformative Learning Theory Perspective
}

\author{
Jian $\mathrm{Li}^{1} \&$ Jinhui $\mathrm{Xu}^{2}$ \\ ${ }^{1}$ School of Education, Indiana University Bloomington, Indiana, United States \\ ${ }^{2}$ Department of Statistics, Indiana University Bloomington, Indiana, United States \\ Correspondence: Jian Li, School of Education, Indiana University, Bloomington, IN 47408, United States. E-mail: \\ j1209@umail.iu.edu
}

Received: July 13, 2016

Accepted: August 6, 2016

Online Published: August 8, 2016

doi:10.5430/ijhe.v5n3p155

URL: http://dx.doi.org/10.5430/ijhe.v5n3p155

\begin{abstract}
The purpose of this study is to investigate the causal relationship between global experience and global competency from a transformative learning theory perspective. China society is becoming more and more linguistically and culturally diverse in a global context. Moreover, Chinese students should be knowledgeable about the international issues to successfully communicate with others in a global world. Hence, in this study, causal inference analysis was used to identify the relations between global experience and global competency methodologically. Cross-cultural experience is essential to enhance students' global competency. Therefore, investigating the relationship between global experience and global competency is significant to develop pedagogical assessments. This study found that the global experience is associated with global competence. Therefore, providing sufficient intercultural opportunities and sustainable funding supports are fundamental for HEIs to improve global competency in contemporary Chinese higher education system.
\end{abstract}

Keywords: Global Experience, Global Competency, Transformative Learning Theory, China's Higher Education

\section{Introduction}

In recent decades, the number of overseas Chinese students has dramatically increased by the trend of globalization of higher education (MOE, 2015). The major challenges of Chinese higher education are to offer students a thorough understanding of the world in a global context. In other words, students should be capable of investigating the world, weighting individual and others' viewpoints, communicating and collaborating with different students, translating their ideas and exploring appropriate behaviors in a global context. Furthermore, intercultural experience is considered as one of the most significant experiences in the $21^{\text {st }}$ century. Facing with the rapid development of global economy, most of higher education institutions are required to promote global educational experiences and opportunities for undergraduate students in current higher education systems. Intercultural experience has been regarded as a crucial index for the degree of globalization in the higher education systems in order to enhance global educational competitiveness. However, there are few studies on investigating the relationship between global experience and global competency for Chinese undergraduate students in higher education system currently. Hence, this study aims to analyze the relationship between global experience and global competency for Chinese undergraduates.

\section{Theoretical Framework}

In this study, transformative learning theory has been utilized to the in-depth understanding of the relationship between global experience and global competency theoretically. Specifically, this theory plays a dominant role in understanding generic learning process and outcomes. As a well-established theoretical framework, transformative learning theory (TLT) is a frequently cited theory in the field of adult education (Taylor, 2007; Tisdell, 2003). Transformative learning theory results from evaluating the outcomes of instrumental and communicative learning (Cranton, 2006; Mezirow, 1991). Therefore, in this study, global experience is viewed as a communicative learning, which focuses on understanding others and making oneself understood by navigating foreign language, values, beliefs and feelings. Specifically, the global experience is also considered as one type of learning experiences to 
improve personal learning capacity. Moreover, it is also related to past experiences' guiding future events based on the communication (Mezirow, 1996).

From a transformative learning perspective, the intercultural experience is rooted in learning process. Specifically, Mezirow (1991) articulated that the transformative learning theory describes the phenomenological experience of diversity education. Additionally, he also summarized that the transformation process has several stages, including a disorienting dilemma, a self-examination, recognition of one's discontent, the processes of transformation, exploration for options, planning of a course of action, acquisition of knowledge and skills, provisional trying of new roles, building of competence, and a reintegration into one's life. Moreover, Mezirow (1997) furthermore identified four major processes of transformative learning, including elaborating existing frames of reference, learning new frames of reference, transforming points of view, and transforming habits of the mind. In other words, acquiring new experience is the nature of transformative learning. Mezirow (1991) suggested that, "action in transformative theory is not only behavior, the effect of cause and effect, but rather 'praxis', the creative implementation of a purpose (p. 12)." Moreover, perspective transformation is important in the field of adult education (Mezirow, 1978). It is precipitated by experiences that can enhance individual competency consistently. "The process of perspective transformation has far reaching implications for the education of adults (Mezirow, 1978, p. 107)." Hence, the learning of perspective transformation is one of the most significant learning in the process of fostering learning experience. In parallel with above illustration, the idea of global competency is considered as one form of adult learning outcomes. Based on this assumption, cultivating global competency could be in consistent with the process of lifelong learning. In addition, Freire (1970) and Mezirow (1978) pointed out that the experience learning as the process of reconstructing meaning was intimately connected with a people growth and development.

Moreover, transformative learning experiences include two facets of educational experience: learning process and interpersonal relationships. Specifically, the learning experience contains holistic core components, including interactive, self-reflective, self-directed, and experiential features. Broadly speaking, human development and consciousness, and critical theory all contribute to illustrate transformative learning experiences. The well-identified learning experience is inherently connected with self-reflection in the study of learning development (K. Taylor, 2000). Furthermore, cognitive dimensions of learning can be interpreted as self-directed nature of the learning process. Hence, transformative learning experience is related to the self-organized and peer-learning process by educational discourses. The holistic approaches of fostering transformative learning experiences provided significant implications for practical learning experiences. More specifically, identifying the relationship between transformative learning experience and cross-cultural competency is significant to the comprehensive understanding of transformative learning theory.

\section{Literature Review}

Generally speaking, it is still controversial to define the concept of global competency from different perspectives. Global competence can improve organizational and individual effectiveness in career successes. In the globally integrated labor market, enhancing global competence can ensure organizational and individual competiveness and effectiveness. It seemed plausible to encourage students to improve global competence to address different issues in response to different foreign tasks. Specifically, different definitions of global competency hold different understanding of global competency. More specifically, global competence refers to the acquisition of global knowledge, understanding of international issues, an ability to learn and work with people from diverse linguistic and cultural backgrounds, proficiency in a foreign language, and improving international skills in interdependent world communities (NEA, 2010). NEA also pointed out several basic elements of global competency, including international awareness, appreciation of cultural diversity, proficiency in foreign languages, and competitive skills. Reimers (200) also highlighted the significance of individual's willingness to learn new culture without confusion and uncertainty of communicating with other cultures. Green and Olson (2003) suggested that cultivating global openness awareness and building tolerance of cultural difference and ambiguity are pivotal to communicating with others in a global world.

From an internationalist perspective, excellent intercultural communication skills and knowledgeable in cross-cultural settings are essential to identifying global competency. Moreover, the concept of global competency refers to the knowledge and skills that help people understand the flat world in which they live, integrate across disciplinary domains to comprehend global affairs and events, and create possibilities to address them (Fernando Reimers, 2009, p. 22). Specifically, Hunter et al. (2006) argued that acquiring global knowledge should be the first step to encourage student to obtain global competence. Moreover, Reimers (2009) further point out that the importance of cultural knowledge in response to cultural empathy and identity. Yu long Li (2013) identified three 
major dimensions of constructing global knowledge, including knowledge on one's own culture in the global context, knowledge about the other culture in question, and understanding of global issues, processes, trends, and systems. Moreover, American Council on Education (2008) argued that global skills should contain several key attributes, including the abilities to acquire, analyze, and evaluate information, think critically and solve practical learning problems, communicate and connect with people from other cultural backgrounds, and use acquired knowledge to extend one's access to learn the unknown. Additionally, global competence is considered as the teachable attribute that can be effectively and completely enhanced by providing students with well-integrated learning opportunities. (Yulong Li, 2013, p. 129). In the $21^{\text {st }}$ century, students should be knowledgeable about international issues to successfully communicate with others. In order to be globally competence, "Students should be able investigate their world, weight their own and others' perspective, communicate and collaborate with diverse audiences, and translate their ideas and findings into appropriate actions to improve conditions (Education in World Affairs and Inter, national Understanding, 2010, p.2)." It is extremely necessary to enhance global competency from political, economic, and cultural perspectives. From the policy implementing perspective, implementing global competency assessment can provide sufficient approach to assesse global curriculum and instructions in response to fostering global communicative collaboration and partnership with international institutions and organizations.

\section{Methodology}

\subsection{Data Description}

This survey focused on examining relationship between global experience and global competency for Chinese undergraduate students in eight universities from Beijing, China. The total sample size is 2,505. In this study, we applied Stata 14.1 to analyze the variables. Specifically, the dependent variable is to measure the global competency performance and we utilized the question of whether read foreign academic papers to assess global competency. The treatment group was divided into two parts: having the experience for intercultural training or internship as a treatment group and not having intercultural training or internship as a control group. In addition, these variables of gender, family geographic location, father's education background, mother's education background, whether be familiar with at least one country's language culture (global knowledge), whether be fluently to read references written by foreign language (global skill), and whether disagree with mother country's culture (global attitude) were utilized as independent variables which could interpret gender, geographic factors, father and mother educational influences, and global knowledge, skill, attitude representatively.

\subsection{Descriptive Statistics Analysis}

Specifically speaking, there are 2,502 samples in total of this survey. For gender, $50.28 \%$ of the whole sample is male and $49.72 \%$ is female; for family geographic location, $29.1 \%$ of the whole population is rural and $71.9 \%$ of it is urban. Moreover, $81.77 \%$ of the total population didn't have the experience for intercultural training or internship compared to $18.23 \%$ of them who hold these intercultural experience; $1.36 \%$ of responders' father wasn't be educated and $98.67 \%$ of the total sample was be educated; $2.72 \%$ of responders' mother wasn't be educated and $97.28 \%$ of them was be educated. Meanwhile, $47.36 \%$ of respondents weren't familiar with at least one countries language culture and $52.67 \%$ of the whole population was familiar with more one foreign languages; $77.94 \%$ respondents couldn't read the foreign reference fluently and $22.06 \%$ of them could fluently read foreign newspaper; $40.57 \%$ of the respondents agreed that they didn't agree with their own country's culture. Additionally, $45.24 \%$ of the respondents didn't read any foreign papers and $54.76 \%$ of them read at least one newspaper. (See Table 1) (See Table 2)

\subsection{Reliability and Validity Analysis}

The reliability and validity of this survey were reported as follows: the coefficient of the internal reliability, Cronbach alpha equals to 0.909 , which demonstrated the data has great internal reliability. In addition, for the validity of the data, the value of Kaiser-Meyer-Olkin (KMO) measure of sampling adequacy is equal to 0.933 , and the $p$-value for Bartlett's test of sphericity is equal to 0 , which indicates that the data is of a great validity and suitable within the data.

\subsection{Data Analysis}

\subsubsection{Causal Inference Analysis}

Generally speaking, causal inference is always characterized as a process of making a conclusion about the causal relations in terms of the conditions of the occurrence of the effect. More importantly, the core discrepancies between the causal inference and inference of correlation is that the former investigate the response of the effect variables when the cause is changed (Pearl, 2009). Specifically, the simple cause-and effect questions are the vehicle to do 
much empirical study in social science although the definitive answers to these cause-and effect problems might not be possible to formulate given limitations. Moreover, the counterfactual model of causality has been advocated in past three decades in accordance with a unified framework for the prosecution of the causal questions. Historically speaking, with the early works on experimental research design by Neyman and Iwaszkiewicz(1935), Fisher(1935) Cochran and Cox(1950) Kempthorne (1952) and Cox(1958), the counterfactual models in causal inference of the observational data were formalized in a lot of contributions by Donald Rubin(1974, 1977, 1978, 1980, 1981, 1990). Statistically, the causal model is always referred to analyze potential outcomes of framework in response to the potential yields of Neyman's work in agricultural statistics (see Gelman and Meng 2004; Rubin 2005). The core assumption of the counterfactual framework is that individual in the population of the interest has different potential outcomes under each treatment level, although individual could be observed in one treatment group at any point. Practically speaking, this counterfactual model also related in the economics (Roy 1951; Quandt 1972), with significant efforts by James Heckman (see Heckman 1974, 1978, 1979, 1989, 1991, 2000), Charles Manski(1995, 2003). Overall speaking, the causal model involves analyzing potential outcomes in the field of statistics, economics, sociology, psychology, and political science.

Table 1Descriptive Data of the Study

\begin{tabular}{|c|c|c|}
\hline Variable & $\mathrm{N}$ & Percentage \\
\hline Sex & 2502 & \\
\hline Male & 1258 & $50.28 \%$ \\
\hline Female & 1244 & $49.72 \%$ \\
\hline Family location & 2502 & \\
\hline Rural & 728 & $29.10 \%$ \\
\hline Urban & 1774 & $70.90 \%$ \\
\hline Intercultural training or internship & 2502 & \\
\hline Have no experience for intercultural training or internship & 2046 & $81.77 \%$ \\
\hline Have experience for intercultural training or internship & 456 & $18.23 \%$ \\
\hline Father's education background & 2502 & \\
\hline Not be educated & 34 & $1.36 \%$ \\
\hline Be educated & 2468 & $98.64 \%$ \\
\hline Mother's education background & 2502 & \\
\hline Not be educated & 68 & $2.72 \%$ \\
\hline Be educated & 2434 & $97.28 \%$ \\
\hline Be familiar with at least one country's language culture & 2502 & \\
\hline Disagree & 1185 & $47.36 \%$ \\
\hline Agree & 1317 & $52.64 \%$ \\
\hline Be fluently to read references written by foreign language & 2502 & \\
\hline Disagree & 1950 & $77.94 \%$ \\
\hline Agree & 552 & $22.06 \%$ \\
\hline Do not agree with mother country's culture & 2502 & \\
\hline Disagree & 1487 & $59.43 \%$ \\
\hline Agree & 1015 & $40.57 \%$ \\
\hline Read foreign academic papers & 2502 & \\
\hline Haven't read foreign academic papers & 1132 & $45.24 \%$ \\
\hline Have read foreign academic papers & 1370 & $54.76 \%$ \\
\hline
\end{tabular}


Table 2Des criptive Statistics of Variables

\begin{tabular}{llllll}
\hline Variable & $\mathrm{N}$ & Mean & Std. Dev. & Min & Max \\
\hline Sex $^{1}$ & 2502 & 0.4972 & 0.5001 & 0 & 1 \\
Family location $^{2}$ & 2502 & 0.7090 & 0.4543 & 0 & 1 \\
Intercultural training or internship $^{3}$ & 2502 & 0.1823 & 0.3861 & 0 & 1 \\
Father's education background $^{4}$ & 2502 & 0.9864 & 0.1158 & 0 & 1 \\
Mother's education background $^{5}$ & 2502 & 0.9728 & 0.1626 & 0 & 1 \\
$\begin{array}{l}\text { Be familiar with at least one country's language } \\
\text { culture }^{6}\end{array}$ & 2502 & 0.5264 & 0.4994 & 0 & 1 \\
$\begin{array}{l}\text { Be fluently to read references written by } \\
\text { foreign language }\end{array}$ & 2502 & 0.2206 & 0.4148 & 0 & 1 \\
$\begin{array}{l}\text { Disagree with mother country's culture } \\
\text { Read foreign academic papers }\end{array}$ & 2502 & 0.4057 & 0.4911 & 0 & 1 \\
& 2502 & 0.5476 & 0.4978 & 0 & 1
\end{tabular}

${ }^{1}$ Male $=0$, female $=1$

${ }^{2}$ Rural $=0$, urban $=1$

${ }^{3}$ No experience for training or internship $=0$, have experience for training or internship $=1$

${ }^{4}$ Not be educated $=0$, be educated $=1$

${ }^{5}$ Not be educated $=0$, be educated $=1$

${ }^{6}$ Disagree $=0$, agree $=1$

${ }^{7}$ Disagree $=0$, agree $=1$

${ }^{8}$ Disagree $=0$, agree $=1$

${ }^{9}$ Haven't ever read $=0$, have ever read $=1$

\subsubsection{Casual Effects}

For a two-group treatment, the potential outcomes of individual are defined as the true values of the outcome of the interest that could result from exposure to the alternative causal effects. The potential outcomes of individual $i$ are $y_{i}{ }^{1}$ and $y_{i}{ }^{0}$, where the superscript 1 signifies the treatment group and the superscript 0 signifies the control the group. Both $y_{i}{ }^{1}$ and $y_{i}{ }^{0}$ exist in framework for each individual; an individual-level causal effect can be described as some contrast between $y_{i}{ }^{1}$ and $y_{i}{ }^{0}$, usually the simple difference $y_{i}{ }^{1}-y_{i}{ }^{0}$. (See Table 3) Moreover, given these definitions of $Y^{1}, Y^{0}$, and $D$ (as well as their realizations $y_{i}^{1}$ and $y_{i}{ }^{0}, d_{i}$ ), we can define the observed outcome variable $Y$ in terms of them. We can observe values for a variable $Y$ as $y_{i}=y_{i}{ }^{1}$ for individuals with $d_{i}=1$ and as $y_{i}=y_{i}{ }^{0}$ for individuals with $d_{i}=0$. The observable outcome variable $Y$ is therefore defined as

$$
\begin{gathered}
Y=Y^{1} \text { if } D=1, \\
Y=Y^{0} \text { if } D=0 .
\end{gathered}
$$

This paired definition is usually written compactly as

$$
Y=D Y^{1}+(1-D) Y^{0}
$$

Table 3: The Fundamental Problem of Causal Inference ${ }^{1}$

\begin{tabular}{ccc}
\hline Group & $Y^{1}$ & $Y^{0}$ \\
\hline Treatment group $(D=1)$ & Observable as $Y$ & Counterfactual \\
Control group $(D=0)$ & Counterfactual & Observable as $Y$ \\
\hline
\end{tabular}

${ }^{1}$ The table is referred from "Counterfactuals and casual inference" (Morgan et.al, 2007).

Average Treatment Effect (ATE) and Average Treatment Effect for the treated (ATT) are utilized in causal inference analysis to estimate average treatment effect for the treat and non-treated groups. Specifically, calculating the individual-level causal effects, we emphasized on the estimation of aggregated causal effects, usually alternative average causal effects. With E[.] denoting the expectation operator from probability theory, the average treatment effect in the population is

$$
\mathrm{ATE}=E\left[Y^{1}-Y^{0}\right]=E\left[Y^{1}\right]-E\left[Y^{0}\right] .
$$

The equation follows the linearity of the expectation operator: the expectation of a difference is equal to the difference of the two expectations. Moreover, we care more about the treatment in the treated group. Therefore, we 
usually take the average treatment effect for the treat (ATT) as the observational index that measure the treatment in the treated group. The ATT is

$$
\mathrm{ATT}=E\left[Y^{1} \mid D=1\right]-E\left[Y^{0} \mid D=1\right]
$$

ATT means the average difference between the observable outcome and the possible outcome if they haven't been trained among the treatment group.

\subsubsection{Propensity Score Matching}

It is inevitable to find a problem that existed in data evaluation in terms of the data do not come from randomized trials but from observational or non-randomized studies. Especially, in nearest-neighbor matching, this problem still influenced the evaluating process of data. Moreover, for settings where the outcome data is already available, one obvious drawback of nearest neighbor matching approach is that it does not necessarily utilize all the data, in that some control individuals, even some of those with propensity scores in the range of the treatment groups' scores, are always discarded and not applied in actual analysis. With the limitation of nearest neighbor matching approach in this study, Rosenbaum and Rubin (1983) proposed propensity score matching as an effective method to reduce the bias in the estimation of treatment effects with observational data sets. With propensity score matching, the influence of bias cannot explain the difference of the outcome, which can efficiently control the bias so that obtain the accurate result.

\subsubsection{Estimation of ATE and ATT}

In this study, propensity score matching was utilized to verify these variables. We predict the propensity scores by logistic regression model. The corresponding model is

$$
\log \frac{D}{1-D}=\gamma_{0}+\gamma_{1} X_{1}+\gamma_{2} X_{2}+\gamma_{3} X_{3}+\gamma_{4} X_{4}+\gamma_{5} X_{5}+\gamma_{6} X_{6}+\gamma_{7} X_{7}+\tau
$$

where we denote $D, X_{1}, X_{2}, X_{3}, X_{4}, X_{5}, X_{6}, X_{7}, \tau$ as intercultural training or internship, sex, family location, father's education background, mother's education background, be familiar with at least one country's language culture, be fluently to read references written by foreign language, disagree with mother country's culture and error term, respectively. The propensity score-matching graph has shown as below. As shown in figure 1, the most of the individuals in treatment group could be matched with a corresponding individual in control group with the method of propensity score matching. Intuitively, it is a very good matching among treatment and control group in this study, which led the following inference more convincible. Specifically, after matching, the difference between treated group and controls group is 0.0542 , and $t$-statistic is larger than 1.96 , which indicates that it is of statistical significance with $95 \%$ significance level. The estimates of ATE and ATT are equal to 0.076 and 0.0586 respectively. The $p$-value for both the estimates of ATE and ATT are smaller than 0.05, which demonstrates the estimates of ATE and ATT are significant within 95\% significance level. The value is very closed to the estimated ATT that we obtained in nearest neighbor matching which is equal to 0.0592 . It is also initially verified by the result of nearest neighbor matching. (See Table 4) (See Table 5)

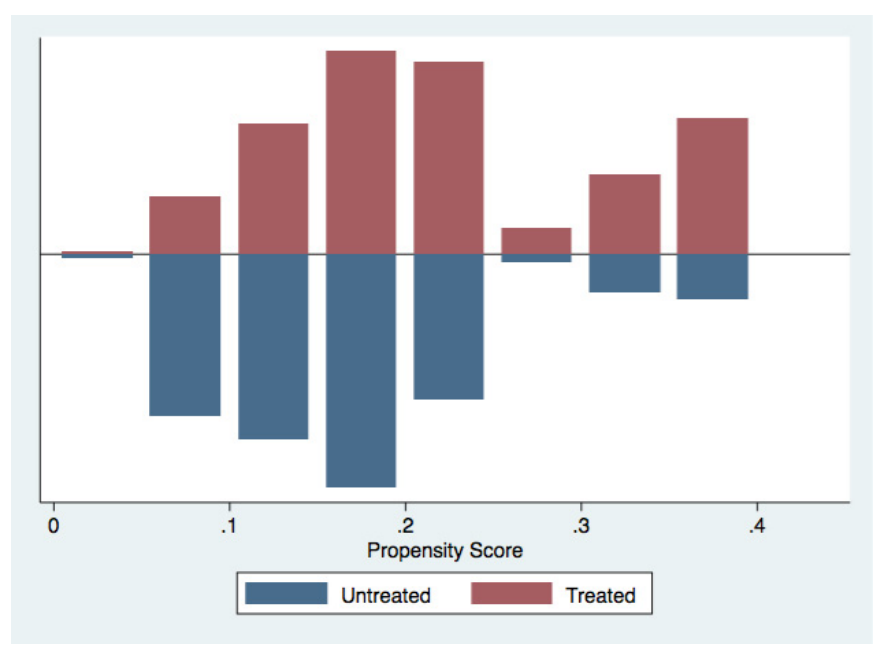

Figure 1. The Propensity Score-matching Graph 
Table 4: Treatment-effects Estimation Model with Propensity-score Matching

\begin{tabular}{llllll}
\hline Read foreign academic papers & Coef. & AI Robust Std. Err. & $z$-stat & \multicolumn{2}{l}{$95 \%$ C.I. } \\
\hline Intercultural training or internship (ATE) & $0.0757^{* *}$ & 0.0280 & 2.70 & 0.0208 & 0.1307 \\
Intercultural training or internship (ATT) & $0.0586^{*}$ & 0.0255 & 2.30 & 0.0087 & 0.1085 \\
\hline
\end{tabular}

Note: ${ }^{* * *} p<0.001 ;{ }^{* *} p<0.01 ;{ }^{*} p<0.05$ (two-tailed tests); $N=2,502$

Table 5: Treatment-effects Estimation Comparison with Propensity-score Matching

\begin{tabular}{lllllll}
\hline Variable & Sample & Treated & Controls & Diff. & Std. Err & $t$-stat \\
\hline Read foreign academic papers & Unmatched & 0.6382 & 0.5274 & 0.1108 & 0.0257 & 4.31 \\
& ATT & 0.6382 & 0.5795 & 0.0586 & 0.0265 & 2.21 \\
\hline
\end{tabular}

\subsubsection{Propensity Score Test}

The propensity score-matching test was conducted to verify whether the bias is reduced in this study and tested the effect and efficiency of the propensity score matching. As shown in Table 6, 7 and 8, for the unmatched samples, the $B$-value, measuring the scale of bias, is 59.2, which indicated that, for unmatched sample, there existed large bias in this model. However, after propensity score matching, the $B$-value is equal to 0.8 , which means almost all the bias are reduced after matching. For gender, father's education background, mother's education background, language culture and mother country's culture, all the bias are reduced, which means the propensity score matching is perfect in this study.

Table 6: The Mean and Bias for Unmatched Sample Before Propensity Score Matching

\begin{tabular}{lllll}
\hline Variable & \multicolumn{2}{c}{ Mean } & \%Bias & $t$-stat \\
& Treated & Control & & \\
\hline Sex & 0.5768 & 0.4795 & 19.6 & 3.77 \\
Family location & 0.8333 & 0.6813 & 36.0 & 6.51 \\
Father's education & 0.9868 & 0.9863 & 0.5 & 0.09 \\
Mother's education & 0.9825 & 0.9707 & 7.8 & 1.40 \\
Language culture & 0.6667 & 0.4951 & 35.3 & 6.69 \\
Fluently read paper & 0.3597 & 0.1896 & 38.8 & 8.02 \\
Mother country's culture & 0.4386 & 0.3983 & 8.2 & 1.58 \\
\hline
\end{tabular}

Table 7: Bias Reduction for Each Variable via Propensity Score Matching

\begin{tabular}{llllll}
\hline Variable & \multicolumn{2}{c}{ Mean } & \%Bias & \%reduct $\mid$ Bias $\mid$ & $t$-stat \\
& Treated & Control & & & \\
\hline Sex & 0.5768 & 0.5768 & 0.0 & 100.0 & 0.00 \\
Family location & 0.8333 & 0.8311 & 0.5 & 98.6 & 0.09 \\
Father's education & 0.9868 & 0.9868 & 0.0 & 100.0 & 0.00 \\
Mother's education & 0.9825 & 0.9825 & 0.0 & 100.0 & 0.00 \\
Language culture & 0.6667 & 0.6667 & 0.0 & 100.0 & 0.00 \\
Fluently read paper & 0.3597 & 0.3618 & -0.5 & 98.7 & -0.07 \\
Mother country's culture & 0.4386 & 0.4386 & 0.0 & 100.0 & 0.00 \\
\hline
\end{tabular}


Table 8: Summary for bias reduction via propensity score matching

\begin{tabular}{lllllll}
\hline Sample & LR chi $^{2}$ & $p>$ chi $^{2}$ & MeanBias & MedBias & B & R \\
\hline Unmatched & 126.61 & 0.000 & 20.9 & 19.6 & $59.2^{*}$ & 1.03 \\
Matched & 0.01 & 1.000 & 0.1 & 0.0 & 0.8 & 0.98 \\
\hline
\end{tabular}

${ }^{*}$ if $\mathrm{B}>25 \%, \mathrm{R}$ outside $[0.5 ; 2$ ]

\subsubsection{Estimate ATT for Matched Samples}

For matched samples, applying the inverse of the estimated propensity scores as weights is to estimate the ATT. As Table 9 shown, after weighting, the estimate of ATT is equal to 0.0556 , with statistical significance and with minor change.

Table 9: ATT estimation for matched samples with the inverse of the estimated propensity scores as weights

\begin{tabular}{llllll}
\hline Read foreign academic papers & Coef. & $\begin{array}{l}\text { Robust } \\
\text { Std. Err. }\end{array}$ & \multicolumn{2}{l}{$\begin{array}{l}\text {-stat } \\
\text { 95\% C.I. }\end{array}$} & \\
\hline Intercultural training or internship & $0.0556^{*}$ & 0.0258 & 2.15 & 0.0050 & 0.1062 \\
(Intercept) & $0.5825^{* * *}$ & 0.0126 & 46.15 & 0.5578 & 0.6073 \\
\hline
\end{tabular}

Note: ${ }^{* * *} p<0.001 ;{ }^{* *} p<0.01 ;{ }^{*} p<0.05$ (two-tailed tests); $N=2,502$

\subsubsection{Sensitivity Analysis}

Generally, the goal of sensitivity analysis is to consider how sensitive the causal estimates are to potential confounders. Specifying and simulating the confounders served as the first step in this analysis. Re-estimating the causal effects with the confounders was included in the model. By changed the degree of confoundness, assessing the extent to which the confounder is to affect the estimates. Additionally, if the $p$-value reaches to 0.05 , we may conclude that the corresponding degree of confoundness would nullify the estimates. For binary confounders, we usually choose Rosenbaum Bounds (Rosenbaum, 2002) to estimate the confounder effects; for continuous confounders, we usually Imbens Partial $R^{2}$ (Imbens, 2003) to estimate. Therefore, the robustness of the model should be tested in this analysis. Since the response variable is binary, using Rosenbaum Bounds to do the sensitivity analysis and Imbens Partial $R^{2}$ are not suitable in this research (See Table 10). Moreover, by increasing the value of confounder $\eta$ we can increase the effects of the confounders. If $\Gamma=1.32$, the bias size is 1.32 , namely, two units with same covariates may differ by 1.32 times in their odds of receiving the treatment because of an unmeasured confounder. According to output above, we observe that 1.32 is the largest value of Gamma, which shows that the model can withstand the exogenous variables well. Hence the model has a relative good rusticity (See Table 11). 
Table 10: Mantel-Haenszel (1959) bounds from 1 to 1.6 for variable Read foreign academic papers

\begin{tabular}{lllll}
\hline Gamma $^{1}$ & $\mathrm{Q}_{-} \mathrm{mh}+{ }^{2}$ & $\mathrm{Q}_{-} \mathrm{mh}^{3}$ & ${ }^{3} \mathrm{mh}+{ }^{4}$ & $p_{-} \mathrm{mh}-{ }^{5}$ \\
\hline 1.00 & 4.2538 & 4.2538 & $1.1 \mathrm{e}-04$ & $1.1 \mathrm{e}-04$ \\
1.05 & 3.7937 & 4.7169 & 0.0001 & $1.2 \mathrm{e}-06$ \\
1.10 & 3.3555 & 5.1591 & 0.0004 & $1.2 \mathrm{e}-07$ \\
1.15 & 2.9376 & 5.5831 & 0.0017 & $1.2 \mathrm{e}-08$ \\
1.20 & 2.5383 & 5.9904 & 0.0056 & $1.0 \mathrm{e}-09$ \\
1.25 & 2.1559 & 6.3825 & 0.0155 & $8.7 \mathrm{e}-11$ \\
1.30 & 1.7890 & 6.7605 & 0.0368 & $6.9 \mathrm{e}-12$ \\
1.35 & 1.4363 & 7.1256 & 0.0755 & $5.2 \mathrm{e}-13$ \\
1.40 & 1.0967 & 7.4787 & 0.1364 & $3.8 \mathrm{e}-14$ \\
1.45 & 0.7692 & 7.8207 & 0.2209 & $2.7 \mathrm{e}-15$ \\
1.50 & 0.4530 & 8.1524 & 0.3253 & $2.2 \mathrm{e}-16$ \\
1.55 & 0.1472 & 8.4743 & 0.4415 & 0 \\
1.60 & 0.0415 & 8.7873 & 0.4835 & 0
\end{tabular}

${ }^{1}$ Gamma: odds of differential assignment due to unobserved factors

${ }^{2} \mathrm{Q} \_\mathrm{mh}+$ : Mantel-Haenszel statistic (assumption: overestimation of treatment effect)

${ }^{3}$ Q_mh-: Mantel-Haenszel statistic (assumption: underestimation of treatment effect)

${ }_{5}^{4} p_{-}$mh+: Significance level (assumption: overestimation of treatment effect)

${ }^{5} p_{-}$mh-: Significance level (assumption: underestimation of treatment effect)

Table 11: Mantel-Haenszel (1959) bounds from 1.3 to 1.35 for variable Read foreign academic papers

\begin{tabular}{|c|c|c|c|c|}
\hline$\overline{\text { Gamma }^{1}}$ & $\mathrm{Q} \_\mathrm{mh}+{ }^{2}$ & ${\mathrm{Q} \_\mathrm{mh}-{ }^{3}}^{3}$ & $\overline{p \_\mathrm{mh}+{ }^{4}}$ & $\overline{p \_\mathrm{mh}{ }^{5}}$ \\
\hline 1.00 & 4.2538 & 4.2538 & $1.1 \mathrm{e}-04$ & $1.1 \mathrm{e}-04$ \\
\hline 1.30 & 1.7890 & 6.7605 & 0.0368 & $6.9 \mathrm{e}-12$ \\
\hline 1.31 & 1.7173 & 6.8345 & 0.0430 & $4.1 \mathrm{e}-12$ \\
\hline 1.32 & 1.6463 & 6.9080 & 0.0499 & $2.5 \mathrm{e}-12$ \\
\hline 1.33 & 1.5757 & 6.9811 & 0.0575 & $1.5 \mathrm{e}-12$ \\
\hline 1.34 & 1.5057 & 7.0536 & 0.0661 & $8.7 \mathrm{e}-13$ \\
\hline 1.35 & 1.4363 & 7.1256 & 0.0755 & $5.2 \mathrm{e}-13$ \\
\hline
\end{tabular}

${ }^{1}$ Gamma: odds of differential assignment due to unobserved factors

${ }^{2}$ Q_mh+: Mantel-Haenszel statistic (assumption: overestimation of treatment effect)

${ }^{3}$ Q_mh-: Mantel-Haenszel statistic (assumption: underestimation of treatment effect)

${ }^{4} p_{-}$mh+: Significance level (assumption: overestimation of treatment effect)

${ }^{5} p_{-}$mh-: Significance level (assumption: underestimation of treatment effect)

\section{Findings}

Cross-cultural experience is essential to enhance students' global competency. Therefore, investigating the relationship between global experience and global competency is significant to develop pedagogical assessments. In a higher education domain, the idea of global competence as one type of learning outcome can be assessed by different statistical methods. From a causal inference analysis, the result initially provided solid evidence that the global experience of intercultural training and internship could be related to student's international competency. More specifically, in this study, a causal analysis has been utilized to investigate the causal relationship between global experience and global competency. For this research, this model demonstrated that the estimation of gender, family geographic location, father's education background and mother's education background are not significant, which indicated these factors may not cause the effect of global competency. This initial outcome indicates the scientificity of the factor selection and it fundamentally consistency with the theory. For a propensity score matching and test, the most of the individuals in treatment group could be matched with a corresponding individual in control 
group with the method of propensity score matching. The $p$-value for both the estimates of ATE and ATT are smaller than 0.05 , which demonstrates the estimates of ATE and ATT are significant within $95 \%$ significance level. The value is very closed to the estimated ATT that we obtained in nearest neighbor matching which is equal to 0.0592 . Meanwhile, the propensity score-matching test was conducted to verify whether the bias is reduced in this study and tested the effect and efficiency of the propensity score matching. Furthermore, in a sensitivity analysis, we could summarize that 1.32 is the largest value of Gamma, which showed that the model can withstand the exogenous variables well. Hence, this model has a relative good rusticity. Based on these results from causal inference analysis, we can summarize that the global experience could promoting the development of global competency statistically.

\section{Conclusion \& Policy Recommendations}

The causal relationship between global experience and global competency has been proofed by the causal inference analysis in this study. Additionally, how to design and implement pedagogical interventions to promote student global experience still challenge policymakers and educators in current global education background. Enhancing global experience is extremely necessary to foster global communication. Moreover, offering global communicative collaboration and partnership with international institutions and organizations is particularly fundamental to identifying and assessing global competency. From a policy implementing perspective, building sufficient and sustainable funding system for improving global experience and opportunities is essential to cultivating global competency for undergraduates in contemporary China's higher education system. Moreover, in the current economic scenario, intercultural training and experiences in global context are consistent with cultivating global knowledge, skills and attitudes. Additionally, this study also provided solid evidences to the advocacy of offering intercultural opportunities or trainings by the means of building adequate educational funding support and providing sufficient intercultural experience and opportunities for undergraduate students in contemporary China's higher education system.

\section{References}

Bok, D. (2006). Our underachieving colleges: A candid look at how much students learn and why they should be learning more. Princeton, NJ: Princeton University Press.

Bok, S. (1995). Common values. University of Missouri Press, Colombia, MO.

Boyd, R. D. (1989). Facilitating personal transformation in small groups. Small Group Behavior, 20, 459-474. http://dx.doi.org/10.1177/104649648902000406

Boyd, R. D. (1991). Mary: A case study of personal transformation in a small group. In Personal transformation in small groups: A Jungian perspective (pp. 179-202). London, England: Routledge. http://dx.doi.org/10.4324/9780203359099_chapter_seven

Boyd, R. D. (1991b). Personal transformation in small groups: A Jungian perspective. London, England: Routledge. http://dx.doi.org/10.4324/9780203359099

Boyd, R. D., \& Myers, J. G. (1988). Transformative education. International Journal of Lifelong Education, 7,261-284. http://dx.doi.org/10.1080/0260137880070403

Cochran, W. G., \& Cox, G. M. (1957). Experimental Designs. Wiley, New York

Cox, D. R. (1958). Planning of experiments. Wiley, New York.

Cranton, P. (1994). Understanding and promoting transformative learning: A guide for educators of adults. San Francisco: Jossey-Bass.

Cranton, P., \& Taylor, E. W. (2012). TL theory. Seeking a more unified theory. In E. W. Taylor \& P. Cranton (Eds.), The handbook of TL: Theory, research and practice (pp. 3-20). San Francisco, CA: Jossey-Bass.

Daloz,L (1999) Mentor: Guiding the journal of adult learners. San Francisco, CA: Jossey-Bass.

Dirkx, J. M. (1998, March). Knowing the self through fantasy: Toward a mytho-vpoetic view of transformative learning. Paper presented at the 39th Annual Adult Education Research Conference

Dirkx, J. M. (2012). Joumey of the self: A Jungian perspective on transformative leaming. In P. Cranton \& E. W. Taylor (Eds.), Handbook of transformative learning (pp. 116-130). San Francisco, CA: Jossey-Bass

Dirkx, J. M. (2012). Joumey of the self: A Jungian perspective on transformative leaming. In P. Cranton \& E. W. Taylor (Eds.), Handbook of transformative learning (pp. 116-130). San Francisco, CA: Jossey-Bass. 
Education in World Affairs and Inter, national Understanding. (2010). Afterschool and Global Competence: Expanding and Enhancing Learning Opportunities Issue Brief No.41, April 2010.

Fantini, A. (2009). Assessing intercultural competence: Issues and tools. In D. K. Deardorff (Ed.), The SAGE handbook of intercultural competence. Thousand Oaks, CA: Sage.

Fantini, A., \& Tirmizi, A. (2006). Exploring and Assessing Intercultural Competence SIT Graduate Institute/ SIT Study Abroad. World Learning Publications.

Fernando Reimers and Eleonora Villegas-Reimers. (2006). "School Culture and Democratic Citizenship in Latin America" in Developing Cultures: Essays in Cultural Change, ed. Jerome Kagan and Lawrence E. Harrison, (pp. 95-114), New York: Routledge.

Fisher, R. A. (1935). The design of experiments. Oliver and Boyd, Edinburgh.

Freiré, P. (1972). Pedagogy of the oppressed. London, England: Penguin

Fuller, A. (2007). Critiquing theories of learning and communities of practice. In J. Hughes, N. Jewson, \& L. Unwin (Eds.), Communities of practice. Critical perspectives (pp. 17-29). Milton Park, England: Routledge. http://dx.doi.org/10.4324/NOE0415364737.ch2

Gelman, A., \& Meng, X. L. (Eds.). (2004). Applied Bayesian modeling and causal inference from incomplete-data perspectives. John Wiley \& Sons. http://dx.doi.org/10.1002/0470090456

Global Competence is a 21st Century Imperative NEA Education Policy and Practice Department | Center for Great Public Schools | 1201 16th St., NW, Washington, D.C. 20036

Green, M., \& Olson, C. (2003). Internationalizing the campus: A user's guide. Washington, DC: American Council on Education.

Gutmann, A. (1999). Democratic Education. Princeton University Press, Princeton, NJ. http://dx.doi.org/10.1515/9781400822911

Heckman, J. J. (1974). Shadow prices, market wages, and labor supply. Econometrica: journal of the econometric society, 679-694. http://dx.doi.org/10.2307/1913937

Heckman, J. J. (1978). Dummy Endogenous Variables in a Simultaneous Equation System. Econometrica, 46(4), 931-959. http://dx.doi.org/10.2307/1909757

Heckman, J. J. (1979). Selection Bias as a Specification Error. Econometrica, 47(1), 153-161. http://dx.doi.org/10.3386/w0172

Heckman, J. J. (1989). Causal inference and nonrandom samples. Journal of Educational Statistics, 159-168. http://dx.doi.org/10.2307/1164605

Heckman, J. J. (1991). Randomization and Social Policy Evaluation. NBER Working Paper, (t0107).

Heckman, J. J. (2000). Causal Parameters and Policy Analysis in Economics: A Twentieth Centaury Retrospective. Quarterly Journal of Economics, 115(1), 45-97. http://dx.doi.org/10.3386/w7333

Hill, D. J. (1991). Global education and the study abroad program. Ohio: Renaissance Publications.

Hunter, B., White, G.P., \& Godbey, G. (2006). What does it mean to be globally competent? Journal of Studies in International Education, 10(3), 267-285. http://dx.doi.org/10.1177/1028315306286930

Huntington, S. P. (1993). The clash of civilizations? Foreign affairs, 22-49. http://dx.doi.org/10.1007/978-1-349-62397-6_6

Imbens, G. W. (2003). Sensitivity to exogeneity assumptions in program evaluation. American Economic Review, 126-132. http://dx.doi.org/10.1257/000282803321946921

Kempthorne, O. (1952). The design and analysis of experiments. Wiley, New York. http://dx.doi.org/10.1097/00010694-195205000-00012

Li, Y. (2012). Cultivating Student Global Competence: A Pilot Experimental Study Decision Sciences Journal of Innovative Education Volume 11 Number 1 January 2013 Printed in the U.S.A.

Manski, C. F. (1995). Identification problems in the social sciences. Harvard University Press, Cam-bridge.

Manski, C. F. (2003). Partial identification of probability distributions. Springer Science \& Business Media. 
Mantel, N., \& Haenszel, W. (1959). Statistical aspects of the analysis of data from retrospective studies. Journal of the National Cancer Institute, 22(4), 719-748. http://dx.doi.org/10.1093/jnci/22.4.719

Merriam, S, B, \& Clark, M, C. (1991). Lifelines: Patterns of work, love, and leaming in adulthood. San Francisco, CA: Jossey-Bass,

Merryfield, M. (2008). Scaffolding social studies for global awareness. Social Education, 72(7), 363-364.

Mezirow, J. (1978). Education for perspective transformation: Women's re-entry programs in community colleges. New York, NY: Teacher's College, Columbia University.

Mezirow, J. (1991). Transformative dimensions of adult leaming. San Francisco, CA: Jossey-Bass

Mezirow, J. (1996). Contemporary paradigms of learning. Adult Education Quarterly, 46(3), 158- 172. http://dx.doi.org/10.1177/074171369604600303

Mezirow, J. (1997). Transformative learning: Theory to practice. New Directions for Adult and Continuing Education, 74, 5-12. http://dx.doi.org/10.1002/ace.7401

Mezirow, J. (1998). Postmodern critique of transformation theory: A response to Pietrykowski. Adult Education Quarterly, 49, 65-76. http://dx.doi.org/10.1177/074171369804900107

Mezirow, J. (2000). Learning to think like an adult: Core concepts of transformation theory. In J. Mezirow \& Associates (Eds.), Learning as transformation: Critical perspectives on a theory in progress (pp. 3-33). San Francisco, CA: Jossey-Bass.

Mezirow, J., \& Associates. (2000). Learning as transformation: Critical perspectives on a theory in progress. San Francisco, CA: Jossey-Bass.

Morgan, S. L., \& Winship, C. (2007). Counterfactuals and Causal Inference: Methods and Principles for Social Research. Cambridge University Press. http://dx.doi.org/10.1017/cbo9780511804564

Nelly Stromquist. (2002). ch. 3, Education in a Globalized World.

Neyman, J., \& Iwaszkiewicz, K. (1935). Statistical problems in agricultural experimentation. Supplement to the Journal of the Royal Statistical Society, 2(2), 107-180. http://dx.doi.org/10.2307/2983637

Olson, C., Green, M., \& Hill, B. (2005). Building a strategic framework for comprehensive internationalization. Washington, DC: American Council on Education.

Patrick, S., \& Sturgis, C. (2011). Cracking the code: Synchronizing policy and practice forperformance-based learning. Vienna, VA: International Association for $\mathrm{K}-12$ Online Learning. Retrieved from:http://www.inacol.org/research/docs/iNACOL_CrackingCode_full_report.pdf

Pearl, J. (2009). Causality: Models, Reasoning and Inference (2nd Edition). Cambridge University Press, Cambridge. http://dx.doi.org/10.1017/cbo9780511803161

Quandt, R. E. (1972). A new approach to estimating switching regressions. Journal of the American statistical association, 67(338), 306-310. http://dx.doi.org/10.1080/01621459.1972.10482378

Rathzel, N., \& Uzzell, D. (2009). Transformative environmental education: A collective rehearsal for reality. Environmental Education Research, 15, 263-277 http://dx.doi.org/10.1080/13504620802567015

Reardon, B. (1997). Tolerance: The threshold of peace. Unesco, Paris.

Reimers, F. (2006). Citizenship, identity and education: Examining the public purposes of schools in an age of globalization. Prospects, 36(3), 275-294. http://dx.doi.org/10.1007/s11125-006-0009-0

Reimers, F. (2009). Educating for Global Competency, Excerpts from Chapter 14 of International Perspectives on the Goals of Universal Basic and Secondary Education, New York: Routledge.

Reimers, F. (2009). Educating for global competency. In J. E. Cohen \& M. B. Malin (Eds.), International perspectives on the goals of universal basic and secondary education, (pp. 183-202), New York: Routledge.

Rosenbaum, P. R. (2002). Covariance adjustment in randomized experiments and observational studies. Statistical Science, 17(3), 286-327. http://dx.doi.org/10.1214/ss/1042727942

Rosenbaum, P. R., \& Rubin, D. B. (1983). Assessing sensitivity to an unobserved binary covariate in an observational study with binary outcome. Journal of the Royal Statistical Society. Series B (Methodological), 212-218. 
Roy, A. D. (1951). Some thoughts on the distribution of earnings. Oxford economic papers, 3(2), 135-146.

Rubin, D. B. (1973). Matching to remove bias in observational studies. Biometrics, $159-183$. http://dx.doi.org/10.2307/2529684

Rubin, D. B. (1974). Estimating causal effects of treatments in randomized and nonrandomized studies. Journal of educational Psychology, 66(5), 688-701. http://dx.doi.org/10.1037/h0037350

Rubin, D. B. (1977). Assignment to Treatment Group on the Basis of a Covariate. Journal of Educational and Behavioral Statistics, 2(1), 1-26. http://dx.doi.org/10.3102/10769986002001001

Rubin, D. B. (1978). Bayesian inference for causal effects: The role of randomization. The Annals of statistics, 34-58. http://dx.doi.org/10.1214/aos/1176344064

Rubin, D. B. (1980). Bias reduction using Mahalanobis-metric matching. Biometrics, $293-298$. http://dx.doi.org/10.2307/2529981

Rubin, D. B. (1981). Estimation in parallel randomized experiments. Journal of educational and behavioral statistics, 6(4), 377-401. http://dx.doi.org/10.3102/10769986006004377

Rubin, D. B. (1990). Formal mode of statistical inference for causal effects. Journal of statistical planning and inference, 25(3), 279-292. http://dx.doi.org/10.1016/0378-3758(90)90077-8

Rubin, D. B. (2005). Causal Inference Using Potential Outcomes: Design, Modeling, Decisions. Journal of the American Statistical Association, 100(469), 322-331.

Splawa-Neyman, J., Dabrowska, D. M., \& Speed, T. P. (1990). On the application of probability theory to agricultural experiments. Essay on principles. Section 9. Statistical Science, 5(4), 465-472. http://dx.doi.org/10.1214/ss/1177012031

Stuart, E. A. (2010). Matching methods for causal inference: A review and a look forward. Statistical science: a review journal of the Institute of Mathematical Statistics, 25(1), 1-21. http://dx.doi.org/10.1214/09-STS313

Taylor, K.(2000). Teaching with developmental intention. In J. Mezirow (Ed.) Learning as transformation: Critical perspectives on a theory in progress(pp. 151- 180), San Francisco, CA: Jossey Bass.

Torres, C. A., \& Schugurensky, D. (2002). The political economy of higher education in the era of neoliberal globalization: Latin America in comparative perspective. Higher Education, 43(4), 429-455. http://dx.doi.org/10.1023/A:1015292413037

Whyte, D. (2002). Crossing the unknown sea: Work as a pilgrimage of identity. New York, NY: Riverhead Books. 